\title{
Glycogen Storage Disease Type IIb
}

National Cancer Institute

\section{Source}

National Cancer Institute. Glycogen Storage Disease Type IIb. NCI Thesaurus. Code C84735.

A genetic metabolic disorder causing hypertrophic cardiomyopathy. Mutations of the LAMP2 gene have been reported in association with this disease. 